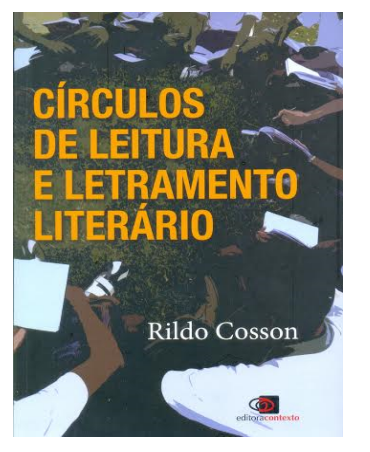

COSSON, Rildo. Círculos de leitura e letramento literário. São Paulo: Contexto, 2014.

\title{
Letramento Literário e Práticas de Leitura
}

Lívia Márcia Tiba Rádis Baptista*

Ao longo dos sete capítulos de Círculos de leitura e letramento literário, Rildo Cosson trata do letramento literário como uma prática de leitura. Inicia com a apresentação de concepção de literatura centrada na palavra e não no impresso, por considerá-la mais dilatada que a usualmente difundida nos livros escolares. No segundo e no terceiro capítulos, aborda, respectivamente, os elementos e objetos de leitura para identificar o lugar do letramento literário como prática de leitura. No quarto capítulo, sistematiza os modos de leitura da literatura culturalmente disponíveis para as comunidades de leitores. No quinto capítulo, associa algumas práticas de leitura literária consideradas relevantes tanto para o letramento literário como para os círculos de leitura. Já no sexto e no sétimo capítulos, discute o funcionamento dos vários tipos de círculos de leitura, enriquecendo sua exposição com exemplos e apresentação de propostas concretas.

Nota-se, ao longo de todos os capítulos, uma organicidade interna que nos leva a (re)pensar e a (re)significar os papéis de leitor, formador de leitores e, ainda, a identidade do sujeito letrado, inserido nas diversas comunidades interpretativas, nas quais os textos literários, em sua acepção ampla, constroem e medeiam relações de sentido. Sendo assim, o autor conduz, em um texto ágil e, simultaneamente, vigoroso e fluido, reflexões

\footnotetext{
* Doutorado em Linguística pela Universidade Estadual de Campinas (2005). Professora associada da Universidade Federal da Bahia. Atua, também, na Universidade Federal do Ceará.Contato: liviarad@yahoo.com
} 
incessantes que desestabilizam visões e concepções de texto, discurso, práticas de leitura e, obviamente, de literatura e literário. Percebe-se em sua exposição uma preocupação constante com as potencialidades do letramento literário, uma prática de leitura que adquire densidade e contorno nas tramas de sentidos dos textos, contextos e intertextos, e que, inevitavelmente, afeta todos os sujeitos leitores. Além desses aspectos, o autor reconhece a dimensão formativa do letramento literário, ao sugerir maneiras de abordar os diversos textos que contribuem para a (trans)formação dos leitores. Chama a atenção que, no final de cada capítulo, surge uma fábula, relacionada com as reflexões desenvolvidas, realimentando um ciclo de inquietações, no qual a palavra torna-se uma bússola desejada para dar o norte, sinalizar o caminho da compreensão da temática explorada.

Teceremos, a seguir, algumas considerações e apreciações sobre determinados tópicos tratados nos diferentes capítulos, haja vista sua relevância para a compreensão do letramento literário como uma efetiva prática de leitura.

Comecemos pelo primeiro capítulo, no qual o autor problematiza como a literatura na atualidade parece não ter lugar no cotidiano e discute o cenário desolador de quem se dedica a ela e ao seu ensino. Refere-se a alguns "índices do apagamento da literatura na escola" (p. 14), associados com o fim de certa tradição escolar que se remonta aos gregos e na qual o uso pedagógico dos textos literários era "meio e fim de um processo educativo", "instrumento de acesso ao mundo da cultura" (p. 15). Entretanto, essa aliança - que traspassou o ensino de línguas clássicas para o da materna - não resistiu às mudanças sociais, pedagógicas e teóricas vivenciadas tanto na escola como pelo alunado no que se refere ao conhecimento de literatura. Ora, esse modelo não condiz com uma prática significativa que contribua para o letramento literário do aluno. Entendemos, consequentemente, que a questão principal consiste em como lidar com esse descompasso, ou seja, como dar uma direção diferenciada à leitura dos textos literários, de forma que não nos aprisionemos em modelos anacrônicos.

O autor segue suas reflexões acerca do lócus da literatura, problematiza a associação literatura, escrita e livro e sugere recuperar uma concepção básica: a da literatura como palavra. Segundo essa concepção, há distintas formas de difusão da literatura, como mostram os diferentes formatos e veículos, seus avatares: a canção popular, o filme, as histórias em quadrinho, a literatura 
eletrônica, as séries televisivas, telenovelas, jogos eletrônicos, propagandas. Dadas as diversas possibilidades para a existência do literário, a literatura atravessa várias manifestações que nos circundam discursivamente. Daí a escolha acertada de "avatar", termo que sugere e evoca essa permanência fluida, híbrida e polissêmica. Em todos os exemplos citados, o trânsito se dá por um terreno comum, qual seja, o do espaço literário. Ora, o autor (des)territorializa a literatura e, simultaneamente, valoriza o que denomina a "palavra feita literária" (p. 19) e sua expansão, reforçando sua presença no nosso cotidiano. Tema que o leva ao debate sobre a circulação e a permanência da literatura, cujo ponto central é o conceito de literatura e, especialmente, a contribuição de Even-Zohar em sua "teoria dos polissistemas" (1990) para a compreensão dos seus modos de existência. Retoma a dicotomia "cultura como bens" ou "produto" e "cultura como instrumento" (p. 24), trasladando-a para a literatura. Para a concepção da literatura como bem ou produto interessa a percepção desse objeto pelo valor, prestígio e status que esse encarna. Já a literatura como instrumento não supõe o conjunto das obras e suas funções sociais inerentes a um dado objeto como o literário, mas o emprego desse conjunto em toda a sua complexidade. De acordo com essa concepção, a literatura é "uma atividade que produz textos" (p. 24) bem como produtores desses textos para elaborar novos produtos e novas formas de fazer literário. Implica um mercado para tais textos, instituições que o mantêm, consumidores que os legitimem como texto e, por fim, um repertório que "alimenta todos com palavras, imagens e modos de viver e interpretar o mundo e o vivido" (p. 25). Como observa Cosson (2014, p. 25), o letramento literário permite a apropriação da literatura como "construção literária de sentidos"; dessa forma, esse repertório é construído, transformado, negociado e preservado tanto individual como socialmente através desse letramento.

No segundo capítulo, o autor se debruça sobre a leitura e seus elementos. Observa que, entre as diversas concepções de leitura, escolherá a da leitura como diálogo, fundamentada no dialogismo bakhtiniano. Coerente com essa concepção, ler é produzir sentidos por meio do diálogo, da conversa; um diálogo com o passado e por meio do qual se criam vínculos entre o leitor, o mundo e os outros leitores. Ao ler acedemos a outras comunidades, ou ainda, a várias comunidades de leitores, o que acentua a natureza da 
leitura como uma prática social e historicamente situada. Assim, como afirma o autor, ler consiste em uma competência individual e social, um processo de produção de sentidos que compreende o leitor, o autor, o texto e o contexto. Esse olhar pressupõe o engajamento do leitor em uma rede de sentidos, ao integrar esse circuito de leitura, e é sumamente útil para compreendermos a proposição da leitura como diálogo e os círculos de leitura.

No terceiro capítulo, o autor trata da leitura e seus objetos. Uma questão crucial diz respeito ao lugar da literatura na formação do leitor e à série de questionamentos que suscita. Retoma-se a discussão sobre a escola e a leitura dos textos literários alertando-se para o fato de que esse não é o único espaço de formação. Sugere-se, assim, uma dessacralização com respeito às práticas de leitura e à formação de leitores, o que valida a concepção de letramento literário como uma prática social e a da leitura como diálogo, e evidencia, mais uma vez, que a literatura está em toda parte.

Ainda nesse capítulo, o autor trata de diversas questões, como a problemática em torno da definição de texto, da delimitação do texto e do discurso literário, e, além disso, a existência das múltiplas manifestações do texto literário. Destacamos o papel que cumpre o leitor na construção do literário, questão examinada a partir do cotejo de duas posições: a de Rosenblat (1994) e a de Miall e Kuiken (1999). A primeira, relacionada com a teoria transacional da obra literária, distingue a experiência da leitura baseada na maneira como o leitor processa o texto e propõe a leitura eferente e a estética. Já a segunda, com a concepção de literariedade, oriunda do formalismo russo, refere-se ao conjunto de elementos estilísticos e linguísticos que caracterizam o texto literário frente ao não literário - recentemente retomada como "produto de um modo distinto de ler" (p. 55), que consiste no modo de ler da literatura. Em ambas as concepções o leitor cumpre um papel relevante na construção do literário, mas esse não está desvinculado dos elementos textuais.

No capítulo quarto, o autor centra-se nos modos de ler o texto literário no interior e fora da escola, examinando essa questão a partir dos quatro elementos do circuito de leitura: leitor, autor, texto e contexto. Retoma a visão triádica contexto-com-o texto, ao redor-do-texto e além-do-texto, por meio da qual apresenta diversas possibilidades de leitura e de exploração de leitura do 
texto literário que, entendemos, convergem para a ampliação do letramento literário e para a formação do leitor, apesar de certos reducionismos a que estão sujeitas, como pondera o autor.

No capítulo quinto, após revisar algumas dessas práticas, o autor destaca como podem contribuir para o letramento literário no ambiente escolar. Esse olhar para a educação e, em concreto, para o contexto escolar situa o letramento literário como um dos diversos letramentos que precisam ser considerados na formação dos sujeitos. De acordo com essa visão, o letramento literário, bem como os demais, integra as diversas práticas de leitura e sua especificidade reside na forma como a palavra é tratada, como serve para a construção de sentidos esteticamente elaborados.

Nos capítulos sexto e sétimo, o autor explicita em que consiste uma comunidade de leitores e ressalta o papel das regras interpretativas da comunidade à qual pertence o leitor - convenções, contextos e instituições , que predeterminam o que é o texto e como deve ser lido. Observa não haver texto ou leitores isolados e, assim, os processos de interpretação e, por conseguinte, a construção dos sentidos são marcados indelevelmente por uma dinâmica relação entre autor, obra e leitor, na qual estão presentes as instituições, o mercado e o repertório que dão suporte e sustentação em grande parte às práticas de leitura de uma comunidade. Esse aspecto é decisivo, pois evidencia como os sujeitos se posicionam ao ler e como esses posicionamentos implicam sua inscrição em uma dada comunidade de prática.

$\mathrm{Na}$ conclusão do livro, o autor nota que um círculo de leitura é uma prática de letramento literário que repercute intensamente tanto em quem participa como no espaço em que essa ocorre. Na escola, essa prática contribui para a aprendizagem através da reflexão coletiva, amplia a capacidade de leitura e desenvolve a competência literária, bem como as diversas habilidades sociais e competências linguísticas. Contudo, observa o autor, não devemos considerar os círculos de leitura "uma panaceia para a aprendizagem da escrita e formação do leitor na escola” (p. 177). O círculo de leitura não deve funcionar isoladamente, mas integrar um programa de leitura que abranja outras atividades que favoreçam a leitura, a formação do leitor e a leitura literária.

Como nota o autor, há duas questões fundamentais para que pensemos o letramento literário e os círculos de leitura. A primeira refere-se ao fato de 
que os passos propostos para o círculo de leitura não constituem mera prescrição, já que "nossa capacidade de aprender vai além de qualquer estratégia ou método didático. A maior prova disso é que o propositor de uma nova metodologia aprendeu certamente dentro dos limites da metodologia anterior que ele critica” (p. 178). A segunda alude à concepção de que os círculos de leitura podem incorporar diversos modos de ler e meios de circulação da literatura. Assim, podem incorporar outras formas de manifestação literária, uma vez que os círculos de leitura são "espaços de compartilhamento", o que evidencia a natureza dialógica da leitura e sua relevância como uma prática social e historicamente situada de construção de sentidos - uma construção humana, já que "ler não tem contraindicação, porque é o que nos faz humanos" (p. 179).

Em face do exposto, o autor conclui que não existe a melhor ou a pior leitura. Assim, em conformidade com esse olhar, todas as práticas de leitura nos humanizam e, humanizando-nos, nos tornam mais próximos e abertos ao diálogo. Portanto, todas essas práticas de leitura do texto literário, como precisamente sugere o autor, são diálogos entre o passado e o presente, através dos quais compartilhamos saberes, experiências e visões de mundo e de vida.

Recebido em: 02/06/2015 Aceito: 22/11/2015 